\title{
How Stable Is Coping in Patients with Neuropsychiatric Symptoms after Acquired Brain Injury? Changes in Coping Styles and Their Predictors in the Chronic Phase
}

Citation for published version (APA):

Wolters Gregório - Claessens, G., Ponds, R. W. H. M., Smeets, S. M. J., Jonker, F., Pouwels, C. G. J. G., \& van Heugten, C. M. (2016). How Stable Is Coping in Patients with Neuropsychiatric Symptoms after Acquired Brain Injury? Changes in Coping Styles and Their Predictors in the Chronic Phase. Journal of Neurotrauma, 33(7), 696-704. https://doi.org/10.1089/neu.2015.3900

Document status and date:

Published: 01/04/2016

DOI:

10.1089/neu.2015.3900

Document Version:

Publisher's PDF, also known as Version of record

Document license:

Taverne

Please check the document version of this publication:

- A submitted manuscript is the version of the article upon submission and before peer-review. There can be important differences between the submitted version and the official published version of record. People interested in the research are advised to contact the author for the final version of the publication, or visit the DOI to the publisher's website.

- The final author version and the galley proof are versions of the publication after peer review.

- The final published version features the final layout of the paper including the volume, issue and page numbers.

Link to publication

\footnotetext{
General rights rights.

- You may freely distribute the URL identifying the publication in the public portal. please follow below link for the End User Agreement:

www.umlib.nl/taverne-license

Take down policy

If you believe that this document breaches copyright please contact us at:

repository@maastrichtuniversity.nl

providing details and we will investigate your claim.
}

Copyright and moral rights for the publications made accessible in the public portal are retained by the authors and/or other copyright owners and it is a condition of accessing publications that users recognise and abide by the legal requirements associated with these

- Users may download and print one copy of any publication from the public portal for the purpose of private study or research.

- You may not further distribute the material or use it for any profit-making activity or commercial gain

If the publication is distributed under the terms of Article 25fa of the Dutch Copyright Act, indicated by the "Taverne" license above, 


\title{
How Stable Is Coping in Patients with Neuropsychiatric Symptoms after Acquired Brain Injury? Changes in Coping Styles and Their Predictors in the Chronic Phase
}

\author{
Gisela Wolters Gregório, ${ }^{1,4}$ Rudolf W.H.M. Ponds, ${ }^{1,2}$ Sanne M.J. Smeets, ${ }^{1}$ Frank Jonker, ${ }^{3}$ \\ Climmy G.J.G. Pouwels, ${ }^{4}$ and Caroline M. van Heugten ${ }^{1,5}$
}

\begin{abstract}
The objective of the study was to examine changes in coping and their predictors in patients in the chronic phase after an acquired brain injury with prominent neuropsychiatric symptoms. Patients with brain injury were recruited from consecutive admissions to the outpatient clinics of four mental health centers in the Netherlands. Patients received psychoeducation and/or one or more individual treatment sessions that were not targeting coping styles. Forty-two patients and thirty-two significant others participated. Patients reported a significantly greater use of passive and avoidance coping than both the general population and patients with brain injury without neuropsychiatric symptoms. There were statistically significant increases in avoidance coping between T1 and T2 $(t=2.0 ; p<0.05)$. Less neuropsychiatric symptoms at T1 were associated with increases in avoidance coping, and more neuropsychiatric symptoms were associated with decreases in avoidance coping $(\beta=-3.3 ; p<0.001)$. Patients' underestimation of their deficits at T1 was associated with greater increases in active coping $(\beta=-2.33 ; p<0.05)$ than were patients' accurate estimation and overestimation of deficits at T1. Self-reported executive functioning at T1 was not associated with changes in coping. In conclusion, avoidance coping increased in the chronic phase after brain injury. The changes in coping could partially be explained by the level of neuropsychiatric symptoms and the level of self-awareness but not by self-reported executive functioning, which should be considered in treatment programs.
\end{abstract}

Key words: adaptation; awareness; brain injuries; executive function; neuropsychiatry; psychological; stroke

\section{Introduction}

$\mathbf{M}$ ANY PATIENTS with acquired brain injury (brain injury) suffer from lifelong difficulties in cognition, emotion, and/or behavior. However, there are large individual differences in the extent to which a person suffers from these consequences. Patients with similar injury types or severity may experience very different adaptation processes, with some patients suffering from major difficulties in daily life and other patients showing no or only minor changes. ${ }^{1}$ One of the factors that emerged to be an important predictor for psychosocial functioning is coping - the way in which individuals address stressful situations. ${ }^{2-7}$ Several studies have suggested that patients in the chronic phase after brain injury use more passive coping styles and less active coping styles than before the brain injury ${ }^{3}$ or compared with the general population. ${ }^{8}$ The use of passive and avoidance coping styles is largely considered to be maladaptive, whereas the use of active coping is considered to be adaptive, although results are less consistent. ${ }^{2,8-12}$ Notably, it has been shown that the use of passive coping styles increases and the use of active coping styles decreases or remains stable when coping is not explicitly taken into account in treatment after brain injury. ${ }^{3,13}$ However, when the use of active coping was explicitly stimulated in a cognitive behavioral treatment program, active coping styles increased. ${ }^{14}$ Increases in active coping styles and decreases in passive coping have been associated with a higher quality of life. ${ }^{13}$

The treatment of patients with brain injury may benefit from identifying variables that are predictive of adaptive changes in coping. To our knowledge, no studies have investigated which factors are able to predict whether coping styles change over time. One factor that has been suggested to influence coping in patients with brain injury is self-awareness. On the one hand, greater selfawareness has been associated with a higher level of nonproductive coping, characterized by avoidance, worry, and self-blame in patients with traumatic brain injury. ${ }^{2}$ Also, Medley and colleagues ${ }^{15}$

\footnotetext{
${ }^{1}$ Department of Psychiatry and Neuropsychology, ${ }^{5}$ Department of Neuropsychology and Psychopharmacology, Maastricht University, Maastricht, the Netherlands.

${ }^{2}$ Adelante, Rehabilitation Centre, Hoensbroek, the Netherlands.

${ }^{3}$ Department Vesalius, Altrecht GGZ, Den Dolder, the Netherlands.

${ }^{4}$ Department Acquired Brain Injury Huize Padua, GGZ Oost Brabant, Boekel, the Netherlands.
} 
found a greater use of emotion-focused coping strategies and a greater use of total coping strategies in patients with traumatic brain injury with good self-awareness. On the other hand, Kortte and colleagues ${ }^{16}$ found that greater awareness was associated with a decreased reliance on avoidant coping. In line with this finding, it has been suggested that self-awareness is a prerequisite for developing optimal coping strategies after a brain injury. ${ }^{17}$ Lundquist and colleagues ${ }^{17}$ found that both self-awareness and coping strategy use increased in patients with acquired brain injury who participated in a group program for anticipatory self-awareness and coping strategies. Also other factors are inconsistently associated with coping, such as cognitive functioning (e.g., executive impairment), personal factors (e.g., age and education), and injuryrelated factors (e.g., time since injury). ${ }^{2,8,10,18-22}$ No associations have been found between coping and other injury-related factors, such as injury type and severity. 2,23,24

Patients who suffer from neuropsychiatric symptoms after brain injury (e.g., aggression and apathy) often are excluded from studies that investigate coping and its predictors after brain injury, despite the fact that there is a high prevalence of neuropsychiatric consequences after brain injury. ${ }^{9,21,24-26}$ Approximately one-third of patients with traumatic brain injury suffer from one psychiatric disorder, ${ }^{27}$ and $40 \%$ suffer from two or more psychiatric disorders. ${ }^{28}$ In stroke patients, the percentages range from $20 \%$ to $35 \%$. $^{29}$ Therefore, the evidence on the role of coping in patients with brain injury cannot be automatically generalized to all patients with brain injury. It is of great importance to study the influence of coping styles in this specific population because these patients often experience more difficulties reintegrating into the community and require long-term and expensive care. ${ }^{27,30}$

In the Netherlands, patients with persistent neuropsychiatric symptoms often are referred to specialized mental health care centers, sometimes after they have received treatment at regular rehabilitation centers. These patients still suffer from serious problems in their daily lives. The main goal of neuropsychiatric treatment in mental health care centers, including neuropsychological treatment, is to regulate or normalize the disruptive behavior. To our knowledge, the influence of neuropsychiatric symptoms on coping has not been investigated, likely because these patients often are excluded and studies are not conducted within the mental health care setting. ${ }^{9,21,24-26}$

In the present study, we therefore investigated three research questions. First, we compared the use of coping styles between patients with neuropsychiatric symptoms after brain injury and the general population and patients with brain injury without neuropsychiatric symptoms. Second, we investigated changes in coping styles over time of patients in the chronic phase after brain injury. Third, we explored the relationships between self-awareness, selfreported executive functioning, and neuropsychiatric symptoms and changes in the use of coping styles.

\section{Methods}

\section{Participants}

Participants were recruited from four outpatient mental health centers in the Netherlands from September 2010 to January 2012 (Altrecht Vesalius, Den Dolder; GGZ Oost Brabant, Huize Padua; Bavo Europoort, Rotterdam; and Propersona, Wolfheze). Participants were patients referred to the outpatient mental health clinic because of one or more neuropsychiatric disorders following brain injury that hindered referral to regular rehabilitation services. A significant other also was included if present; this was the person that had the most frequent contact with the patient, according to the patient. Inclusion criteria for the patients were as follows: age
18 or older, brain injury confirmed by neurological and/or neuroimaging data, at minimum one neuropsychiatric disorder severe enough to be referred for specialized mental health care, and a time period of at least 6 months since their injury. Exclusion criteria were an insufficient command of the Dutch language, an inability to complete questionnaires on the basis of clinical judgment, a score of $>24$ on the Structured Inventory of Malingered Symptomatology, ${ }^{31}$ or the presence of degenerative brain disease or whiplash. The significant others were included if they were 18 years or older, knew the patient well (before and after injury), and had frequent contact with the patient. Significant others were excluded if they had insufficient command of the Dutch language, were unable to complete the questionnaires on the basis of clinical judgment, or had a neurological or psychiatric disorder. All participants signed an informed consent for us to use the clinical and test data for this study.

\section{Procedure}

The psychiatrist or neuropsychologist conducted intakes with all patients. The first assessment, T1, was conducted after the intake. Patients completed neuropsychological tests and self-report questionnaires at the center during regular neuropsychological testing. Tests included the Trail Making Test and the Stroop Color Word Test (Stroop) ${ }^{32-34}$ Questionnaires included the Utrecht Coping List (UCL), the Frontal Systems Behavioral Scale (FrSBe), the Awareness Questionnaire (AQ), the Life Satisfaction Questionnaire (LiSat-9), and the Patient Health Questionnaire (PHQ-9). Significant others completed the Neuropsychiatric Inventory (NPI), the $\mathrm{AQ}$, and the FrSBe at home or at the center. Clinicians completed the AQ. The patients, significant others, and the clinicians completed the questionnaires individually and separately. Afterwards, a full report was written and provided to the patient and used for regular care. After the assessment, the psychiatrist or neuropsychologist planned further treatment. All patients received one or multiple sessions of psychoeducation tailored to the patient's cognitive or neuropsychiatric profile. Some patients received an individualized treatment program at the mental health center or the referral institution. The duration of the treatment was different for each individual and determined by the time that patients needed to meet their own goals. There was no explicit focus on changing the use of coping styles in any of the participating centers. However, patients were implicitly helped to address the sequelae of their injuries and find a balance in their mental activities. The patients received on average 1 hour of individual treatment per week, with the frequency varying strongly per patient.

The second assessment, T2, was completed by patients 6 months later individually at home or at the center. The patients completed the UCL. Only the data of patients who completed both assessments were included in the present study.

Patients' demographic information (i.e., age, education level, and gender) and injury-related information (i.e., type of injury, time since injury, Diagnostic and Statistical Manual of Mental Disorders, Fourth Edition (DSM-IV) diagnosis, Global Assessment of Functioning (GAF) score, type of referral, and current psychopharmacological medication) was collected from their medical files by a psychologist or psychology intern. Educational level was assessed according to the standardized Dutch schooling system. ${ }^{35}$ The categories were reduced to primary and junior vocational education [1-4] and senior vocational training [5-8], corresponding to $8.6+1.9,11.4+2.5$, and $15.2+3.3$ years of full-time education, respectively.

The neuropsychologist or psychiatrist had determined the DSMIV diagnosis and GAF score after the intake, in consultation with the treatment team. The GAF is a clinical judgment of symptoms and level of psychological, social, and occupational functioning, with scores ranging from 0 to 100 . Higher scores indicate fewer symptoms, that is, a higher level of functioning. ${ }^{36}$ Significant 
others' age and gender were collected by specific questions in the questionnaires of significant others. Significant other's relationship with the patient was collected with the AQ.

The Medical Ethics Committee of Maastricht University and the Research Committees of each of the four participating institutions approved the study procedures.

\section{Measurements}

UCL. The UCL is a self-report questionnaire used to measure the use of coping styles in handling everyday problems that are not specifically related to brain injury. Each of the 47 items is answered on a 4-point scale, with higher scores indicating a higher use of a particular coping style. The present study focused on three subscales that are often reported in the literature and differentiate both focus (emotion vs. problem) and approach (active vs. passive): the active problem-focused coping subscale (UCLactive; e.g., "tackling a single problem all at once") and the passive reactions and avoidance subscales (UCLpasssive, UCLavoidance), which are two types of emotion-focused coping (e.g., "taking refuge in fantasies"). These scales should be interpreted independently, indicating, for example, that high UCLactive scores do not necessarily correspond to low UCLpassive or UCLavoidance scores. We computed change scores by subtracting the scores at $\mathrm{T} 1$ from the scores at T2 ( $\triangle \mathrm{UCLactive,} \Delta \mathrm{UCLpassive,} \Delta \mathrm{UCLavoidance)}$ ). The UCLactive and UCLpassive consist of seven items; the UCLavoidance consists of eight items. ${ }^{37-39}$ The scales showed a sufficient internal consistency in the general Dutch population (Cronbach's $\alpha=0.74-0.79$ ). We also used normative data from a previous study, in which patients with brain injury with cognitive symptoms but without neuropsychiatric symptoms participated. ${ }^{8}$ In the present study, the Cronbach's $\alpha$ were 0.87 for UCLactive, 0.74 for UCLpassive, and 0.68 for UCLavoidance.

FrSBe. The FrSBe is a 46-item behavior rating scale intended to measure behavior associated with damage to the frontal systems of the brain. ${ }^{40}$ In the present study, we used the Executive Dysfunction subscale, which was completed by both patients (FrSBe-P) and significant others (FrSBe-other). This scale consists of 17 items on which higher scores represent more self-reported executive dysfunction. Cronbach's $\alpha$ coefficients for this measure are sufficiently high, ranging from 0.72 to 0.94 in normative, neurologic, and schizophrenic samples. Further, previous data suggest that the scale has strong construct, discriminant, convergent, and ecological validity. ${ }^{41} \mathrm{We}$ transformed the raw scores into T-scores and used normative tables from the manual to assess the level of executive dysfunction. ${ }^{40}$

NPI. The NPI is a tool originally designed to assess 10 behavioral disturbances occurring in dementia patients. The NPI evaluates the following 12 neuropsychiatric domains: delusions, hallucinations, agitation/aggression, dysphoria/depression, anxiety, apathy, irritability, euphoria, disinhibition, aberrant motor behavior, nighttime behavior disturbances, and appetite and eating abnormalities. If the significant other indicates that a behavioral change is present, the frequency and severity of the behavior is determined. Frequency is rated on a scale of 1 to 4 , and severity is scored from 1 to 3 . A total NPI score was calculated by multiplying the frequency scores and severity scores per domain and summing these index scores (total NPI). The content validity, concurrent validity, inter-rater reliability, and test-retest reliability of the NPI have been established. ${ }^{42,43}$

AQ. The AQ is a 17-item questionnaire used to assess impaired self-awareness after traumatic brain injury. Respondents are asked to rate how well the patient performs a variety of activities, compared with before the injury, with responses ranging from 1 (much worse) to 5 (much better). The patient rates his own behavior, and the significant other and clinician rate the patient's behavior. The discrepancy between the patient's score and the significant other $\left(A Q_{p \text { vs. other }}\right)$ or clinician $\left(A Q_{p \text { vs. }}\right)$ score can be used as a measure of self-awareness. The discrepancy score is calculated by subtracting the significant other's or clinician's score from the patient's score; the greater the discrepancy, the more impaired the patient's self-awareness (range -68 to 68 ). ${ }^{44}$ Positive discrepancies indicate an overestimation and negative discrepancies indicate underestimation of difficulties. ${ }^{45}$ Additionally, we formed three groups (i.e., patients who underestimated, accurately estimated, and overestimated their competencies) based on a method used by Prigatano and Altman. ${ }^{46}$ In the current sample, the internal consistencies for all three forms were good (Cronbach's $\alpha=0.80-0.87$ ).

LiSat-9. The LiSat-9 is a generic self-report instrument for measuring quality of life. ${ }^{47}$ The questionnaire consists of nine items and measures nine domains of life satisfaction. We were interested in the domain of general life satisfaction and therefore only used the item "general satisfaction with life." This item can be rated using a 6-point scale on which higher scores indicate a better quality of life. The Dutch translation of the LiSat-9 previously was used in a study with individuals who had suffered a stroke and showed good reliability (Cronbach's $\alpha=0.82){ }^{48}$

PHQ-9. The PHQ-9 is a 9-item self-report measure that assesses the nine DSM-IV criteria of depression on a 4-point Likert scale. Scores range from 0 to 27, with higher scores indicating more severe levels of depressive symptoms. ${ }^{49}$ Cronbach's $\alpha$ for this measure has ranged from 0.86 to 0.89 in several samples. ${ }^{49}$ The PHQ-9 has also been validated in a sample of individuals with traumatic brain injury. ${ }^{50}$

\section{Statistical analyses}

Descriptive and frequency analyses of the scores on the questionnaires and neuropsychological tests were performed.

To study our first aim, we performed one-sample $t$-tests to investigate differences in UCLactive, UCLpassive, and UCLavoidance between patients in the study and persons of the normative samples. Since the normative samples are split by gender, we performed analyses for men and women separately. ${ }^{8,38}$ Test values of the normative sample of Schreurs and colleagues ${ }^{38}$ that were used in the one sample t-tests were for the men and women, respectively, 18.3 and 19.3 for UCLactive, 10.7 and 10.9 for UCLpassive, and 14.8 and 15.2 for UCLavoidance. Test values for the normative sample of Wolters and colleagues were for the men and women, respectively, 17.6 and 17.3 for UCLactive, 12.0 and 12.5 for UCLpassive, and 16.2 and 16.4 for UCLavoidance. ${ }^{8}$

To study our second aim, we performed paired $t$-tests to investigate the changes in coping (UCLactive, UCLpassive, UCLavoidance) between $\mathrm{T} 1$ and $\mathrm{T} 2$.

To study our third aim, we performed Pearson's productmoment correlation coefficient analyses to investigate the association between self-reported executive functioning (FrSBe-P), neuropsychiatric symptoms (NPI), and self-awareness $\left(A_{p}\right.$ vs. $C$ and $\left.\mathrm{AQ}_{\mathrm{p} \text { vs. other }}\right)$ at $\mathrm{T} 1$ and changes in coping between $\mathrm{T} 1$ and $\mathrm{T} 2$ ( $\triangle$ UCLactive, $\Delta$ UCLpassive, $\Delta$ UCLavoidance). Significant variables were entered as independent variables in one of three multiple linear regression analyses. In these analyses, the dependent variables were $\triangle U C L a c t i v e, \triangle U C L$ passive, or $\triangle U C L a v o i d a n c e$, respectively. Covariates were the patients' demographic variables (i.e., age, gender, and education).

Power analysis for the multiple regression analyses led to an estimated number of 40 participants required, given $\alpha=0.05$, four predictors in the model, large effect size (i.e., Cohen's f $2=0.35$ ), and power $=0.80$. The assumptions of one-sample $t$-tests and regression analysis were checked. The assumptions of regression analysis were met. For the one-sample $t$-tests, we found one outlier. However, excluding this outlier from the analyses did not change 
the results of the analyses, and therefore was included. A $p$ value $<0.05$ was considered statistically significant. Changes in coping scores between $\mathrm{T} 1$ and $\mathrm{T} 2>10 \%$ were considered to be clinically significant. All statistical analyses were conducted using SPSS 22.0 for Mac OS X (Armonk, NY).

\section{Results}

\section{Sample characteristics}

In total, there were 42 patients who completed assessments at both T1 and T2. Demographic and injury-related characteristics are displayed in Table 1. Most participants fit the diagnostic criteria for a cognitive disorder as the first DSM-IV diagnosis (81\%). The mean GAF score (54.6) indicated that the patients in general suffered from moderate symptoms (e.g., flat affect and circumstantial speech) or experienced moderate difficulty in social, occupational, or school functioning (e.g., few friends, conflicts with peers). However, $26 \%$ of the patients suffered from more serious symptoms (i.e., GAF score 35-50; e.g., suicidal ideation), a major impairment in one or several areas (e.g., work or school, family relations, judgment, thinking, or mood), or some impairment in reality testing or communication (e.g., speech is at times illogical). Many patients used psychopharmacological medication $(81 \%)$, with the majority of participants using anxiolytics (33\%), antidepressants $(55 \%)$, or another medication $(83 \%)$, such as medication for somatic complaints. Most patients suffered a single traumatic brain injury or stroke ( $96 \%$ and $62 \%$, respectively). The other patients reported two injuries to the brain.

Thirty-two significant others participated in the study $(69 \%$ female). The mean age of the significant others was $52.1(\mathrm{SD}=8.8$; range, 34.1-70.9). The majority of the significant others was the patients' partner (48\%). In $21 \%$ of the cases, the significant other was a parent, followed by a friend $(5 \%)$ or another family member ( $2 \%$ ). In $24 \%$ of the cases, there was no information available about the type of relationship.

Table 2 and Table 3 present an overview of the scores on the questionnaires and neuropsychological tests. The most frequently reported neuropsychiatric symptoms on the NPI were irritability $(62 \%)$ and depression (48\%). Fifty-seven percent of all patients reported clinically significant executive dysfunction on the FrSBe$P(t>65)$. Forty-one percent of the significant others rated the patient's executive functioning as clinically impaired (FrSBeother; $t>65$ ). Based on the mean scores on the $A Q_{p}$ versus $C$, patients had accurate self-awareness of their deficits. However, when dividing the patients into three groups, we found that $38 \%$ of the patients underestimated, 55\% accurately estimated, and $7 \%$ overestimated their competencies. Based on the mean scores on the $\mathrm{AQ}_{\mathrm{p} \text { versus other }}, 10 \%$ underestimated, $71 \%$ accurately estimated, and $19 \%$ overestimated their competencies. On the LiSat $-9,74 \%$ of all participants reported a low quality of life (score 1 to 4 ). On the PHQ-9, 57\% of patients reported mild to moderate depressive symptoms (score 5-14). Seventeen percent of the patients indicated

Table 1. Patient Characteristics

\begin{tabular}{|c|c|c|c|c|c|}
\hline & \multicolumn{3}{|c|}{$\begin{array}{l}\text { Brain injury neuropsychiatric } \\
\text { sample }(\mathrm{n}=42)\end{array}$} & \multicolumn{2}{|c|}{$\begin{array}{l}\text { Brain injury non-neuropsychiatric } \\
\text { sample }(\mathrm{n}=136)\end{array}$} \\
\hline & Mean $(S D)$ & Median & Range & Mean $(S D)$ & Range \\
\hline \multicolumn{6}{|l|}{ Age (years) } \\
\hline At injury ${ }^{+}$ & $33.5(14.3)$ & 32.6 & $7.0-57.8$ & $42.2(15.0)$ & $0.5-69.7$ \\
\hline At $\mathrm{T} 1$ & $43.8(12.3)$ & 44.3 & $20.8-64.3$ & $45.0(13.6)$ & $17.0-71.0$ \\
\hline \multicolumn{6}{|l|}{ Time (years) } \\
\hline Between injury $^{+}$and $\mathrm{T} 1$ & $10.3(10.1)$ & 7.8 & $0.6-31.2$ & $2.8(4.9)$ & $0.5-31.2$ \\
\hline \multirow[t]{2}{*}{ GAF } & $54.7(6.9)$ & 55 & $35-65$ & & \\
\hline & Frequency & $\%$ & & Frequency & \\
\hline \multicolumn{6}{|l|}{ Sex } \\
\hline Woman & 13 & 31 & & 53 & 39 \\
\hline \multicolumn{6}{|l|}{ Education level } \\
\hline High* & 10 & 24 & & 46 & 34 \\
\hline \multicolumn{6}{|l|}{ Psychopharmacological medication } \\
\hline Yes & 33 & 81 & & & \\
\hline \multicolumn{6}{|l|}{ Type of referral } \\
\hline General practitioner & 17 & 41 & & & \\
\hline Psychologist/social worker & 10 & 24 & & & \\
\hline Psychiatrist & 9 & 21 & & & \\
\hline Rehabilitation or medical doctor & 6 & 14 & & & \\
\hline \multicolumn{6}{|l|}{ Type of brain injury } \\
\hline Traumatic brain injury & 22 & 52 & & 39 & 29 \\
\hline Stroke & 13 & 31 & & 60 & 44 \\
\hline Other ${ }^{\S}$ & 7 & 17 & & 37 & 27 \\
\hline
\end{tabular}

${ }^{+}$If multiple injuries; this is the age at/time since latest injury.

*Senior vocational education, corresponding to $15.2+3.3$ years of full-time education.

${ }^{\S}$ Tumor $(n=3)$, intoxication $(n=2)$, infection $(n=1)$, not specified $(n=1)$.

GAF, Global Assessment of Functioning Scale. 
Table 2. Scores on Questionnaires Completed by Patients and Significant Others

\begin{tabular}{|c|c|c|c|c|c|c|c|c|c|}
\hline & \multicolumn{4}{|c|}{$T 1$} & \multicolumn{4}{|c|}{$T 2$} & \multirow[b]{2}{*}{$\mathrm{p}$ values } \\
\hline & $\mathrm{n}$ & Mean (SD) & Median & Range & $\mathrm{n}$ & Mean (SD) & Median & Range & \\
\hline LiSat-9 & 42 & $3.7(1.3)$ & 4 & $1-6$ & & & & & \\
\hline PHQ-9 & 42 & $9.0(5.9)$ & 8 & $0-24$ & & & & & \\
\hline NPI & 29 & $23.3(14.7)$ & 20 & $2-58$ & & & & & \\
\hline FrSBe-P & 41 & $43.3(9.4)$ & 44 & $19-62$ & & & & & \\
\hline FrSBe-other & 31 & $43.6(12.4)$ & 46 & $23-65$ & & & & & \\
\hline $\mathrm{AQ}_{\mathrm{p} \text { vs. } \mathrm{C}}$ & 42 & $0.6(8.8)$ & 1.0 & $-28.5-22.1$ & & & & & \\
\hline$A Q_{p}$ vs. other & 31 & $2.6(7.6)$ & 1.1 & $-9.6-19.1$ & & & & & \\
\hline UCLactive & 42 & $16.8(4.6)$ & 17 & 8-27 & 42 & $16.1(4.2)$ & 16 & $8-27$ & 0.096 \\
\hline UCLpassive & 42 & $15.2(4.0)$ & 15 & $7-22$ & 42 & $15.6(4.8)$ & 15 & $7-27$ & 0.422 \\
\hline UCLavoidance & 42 & $17.4(3.8)$ & 17 & $9-26$ & 42 & $18.3(3.8)$ & 18 & $9-26$ & 0.048 \\
\hline Trail Making Test (B/A) & 42 & $2.4(0.8)$ & 2.3 & $0-4.6$ & & & & & \\
\hline Stroop Interference & 41 & $53.9(33.5)$ & 48.5 & $6.5-184$ & & & & & \\
\hline
\end{tabular}

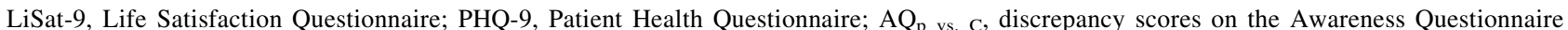
between patient and clinician; $\mathrm{AQ}_{\mathrm{p} \text { vs. other }}$, discrepancy scores on the Awareness Questionnaire between patient and significant other; FrSBe-P, Frontal Systems Behavioral Scale completed by patients; FrSBe-other, Frontal Systems Behavioral Scale completed by significant others; UCLactive, Utrecht Coping List-active subscale; UCLpassive, Utrecht Coping List-passive subscale; UCLavoidance, Utrecht Coping List-avoidance subscale; Trail Making Test (B/A), time on card B divided by time on card A; Stroop Interference, mean time on card I and II subtracted from mean time on card III

moderately severe to severe depressive symptoms (score 15-25). The mean score on the Trail Making Test was 2.4, which is below the cut-off of 3 . However, $21 \%$ of the participants had a score higher than 3 , indicating difficulties with mental flexibility. ${ }^{51}$ The mean Stroop score was 53.9, representing below average performance, and $24 \%$ of the participants exhibited very poor performance $\left(<-2\right.$ standard deviations). ${ }^{33}$

\section{Comparison of coping at $T 1$ and two normative groups}

In general, patients' scores on UCLpassive and UCLavoidance were higher than both the normative sample ${ }^{38}$ and the patients with brain injury without neuropsychiatric symptoms. ${ }^{8}$ That is, the difference on the UCLpassive and the UCLavoidance between the patients in the current study and the normative sample was

Table 3. Scores on the NPI Completed By Significant Others

\begin{tabular}{lccc}
\hline NPI symptoms & $\begin{array}{c}\text { Frequency } \\
\text { (mean) } \\
\text { yes (\%) }\end{array}$ & $\begin{array}{c}\text { Reverity (mean) } \\
\text { Range 1-3 }\end{array}$ \\
\hline Delusions & 10 & 1.5 & 1.6 \\
Hallucinations & 2 & 1.0 & 1.0 \\
Agitation/aggression & 31 & 1.8 & 1.7 \\
Dysphoria/depression & 48 & 1.9 & 2.0 \\
Anxiety & 29 & 2.2 & 1.9 \\
Euphoria & 26 & 2.1 & 1.8 \\
Apathy & 31 & 1.9 & 1.9 \\
Disinhibition & 31 & 2.2 & 2.3 \\
Irritability & 62 & 2.4 & 2.2 \\
Aberrant motor & 12 & 2.6 & 1.2 \\
$\quad$ behavior & & & \\
Nighttime behavior & 29 & 2.6 & 2.0 \\
$\quad$ disturbances & & & \\
Appetite and eating & 33 & 2.9 & 2.3 \\
$\quad$ abnormalities & & & \\
\hline
\end{tabular}

NPI, Neuropsychiatric Inventory. significant (UCLpassive $\mathrm{t}(28)=5.3, p<0.01$ and $\mathrm{t}(12)=5.3, p<0.01$, for men and women, respectively; UCLavoidance $\mathrm{t}(28)=2.6, p<0.05$ and $\mathrm{t}(12)=3.9, p<0.01$, for men and women, respectively). Further, the patients' scores on the UCLpassive and the UCLavoidance were higher, compared with the patients with brain injury without neuropsychiatric symptoms (UCLpassive $\mathrm{t}(28)=3.5, p<0.01$ and $\mathrm{t}(12)=3.8, p<0.01$, for women and men, respectively; UCLavoidance $\mathrm{t}(12)=2.7, p<0.05$, for women). There were no significant differences between the patients in the present study and those in the normative groups on UCLactive $(p>0.05)$.

\section{Changes in coping styles between T1 and T2}

On a group level, there were statistically significant changes in scores on UCLavoidance between T1 and T2 $(\mathrm{t}(41)=2.037, p<.05)$. This change, however, was not clinically significant, indicated by an increase in avoidance scores of less than $10 \%$. There were no significant changes on the UCLactive and UCLpassive coping scales between $\mathrm{T} 1$ and $\mathrm{T} 2$.

\section{Influence of neuropsychiatric symptoms, self-awareness, and executive functioning at T1 on changes in coping styles between T1 and T2}

Although there were no significant changes on the UCLactive and UCLpassive coping scales, we investigated whether the individual variation of the change scores was influenced by neuropsychiatric symptoms, self-awareness, and executive functioning or if it was caused by chance.

Correlation analyses showed that $\mathrm{AQ}_{\mathrm{p}}$ vs. $\mathrm{C}$ at $\mathrm{T} 1$ was significantly associated with $\triangle \mathrm{UCLactive}$ and $\triangle \mathrm{UCLpassive,}$ $(\mathrm{r}(41)=-0.36, p<0.05$ and $\mathrm{r}(41)=0.38, p<0.05$, respectively $)$. These results indicated that patients who underestimated their deficits reported greater increases in active coping and greater decreases in passive coping than patients who accurately estimated and overestimated their deficits. To further interpret this relationship, we explored the UCL changes per awareness group. There were no significant associations between $A Q_{p}$ vs. $c$ and $\Delta U C L a c t i v e$ and $\Delta U C L$ passive per group. Total scores on the 
NPI at T1 were significantly associated with $\Delta$ UCLavoidance $(\mathrm{r}(28)=-0.46, p<0.05)$. More specifically, patients with less neuropsychiatric symptoms reported increases in avoidance coping, and patients with more neuropsychiatric symptoms reported decreases in avoidance coping. Scores on the FrSBe-P and FrSBeother were not associated with $\triangle U C L a c t i v e, \triangle U C L p a s s i v e$, or $\Delta \mathrm{UCLavoidance}(p>0.05)$.

Three multiple regression analyses were performed. The negative association between $A_{p}$ vs. $c$ and $\Delta$ UCLactive was still significant after correcting for demographic variables (Table 4, model 1). This supported the finding that patients who underestimated their deficits reported greater increases in active coping and greater decreases in passive coping than patients who accurately estimated and overestimated their deficits. The association between $A Q_{p}$ versus $C$ and $\Delta U C L$ passive approached significance after correction (Table 4, model 2). The negative relationship between total NPI scores and $\triangle$ UCLavoidance was still significant after correction (Table 4, model 3), supporting that patients with less neuropsychiatric symptoms reported increases in avoidance coping, and patients with more neuropsychiatric symptoms reported decreases in avoidance coping. The models explained between $17 \%$ and $39 \%$ of the variance in $\triangle \mathrm{UCL}$ scores, respectively.

\section{Discussion}

The objectives of this study were to investigate the difference in the use of coping styles between patients with neuropsychiatric symptoms after brain injury and the general population and patients with brain injury without neuropsychiatric symptoms, along with changes in coping styles over time and their predictors. Patients reported a greater use of passive and avoidance coping than both the

Table 4. Linear Multiple Regression Models with Changes in Coping as the Dependent Variable

\begin{tabular}{|c|c|c|c|c|c|c|}
\hline & $B$ & $S E$ & $\beta$ & $t$ & $\mathrm{P}$ & $R^{2}$ \\
\hline \multicolumn{7}{|c|}{ Model 1: $\Delta$ UCLactive } \\
\hline (Constant) & -0.47 & 1.517 & & -0.31 & 0.76 & \\
\hline Age & 0.01 & 0.03 & 0.03 & 0.18 & 0.86 & \\
\hline Gender & -0.39 & 0.92 & -0.07 & -0.43 & 0.67 & \\
\hline Education & -1.21 & 0.93 & -0.20 & -1.30 & 0.20 & \\
\hline $\mathrm{AQ}_{\mathrm{p} \text { vs. C }}$ & -0.11 & 0.05 & -0.38 & $-2.33^{*}$ & 0.03 & 0.17 \\
\hline \multicolumn{7}{|c|}{ Model 2: $\triangle$ UCLpassive } \\
\hline (Constant) & 1.85 & 1.97 & & 0.94 & 0.35 & \\
\hline Age & -0.03 & 0.04 & -0.10 & -0.65 & 0.52 & \\
\hline Gender & -1.20 & 1.19 & -0.16 & -1.01 & 0.32 & \\
\hline Education & 0.34 & 1.20 & 0.04 & 0.28 & 0.78 & \\
\hline $\mathrm{AQ}_{\mathrm{p} \text { vs. C }}$ & 0.12 & 0.06 & 0.32 & 1.98 & 0.06 & 0.17 \\
\hline \multicolumn{7}{|c|}{ Model 3: $\triangle$ UCLavoidance } \\
\hline (Constant) & 2.30 & 1.48 & & 1.56 & 0.13 & \\
\hline Age & 0.02 & 0.03 & 0.09 & 0.55 & 0.59 & \\
\hline Gender & -1.99 & 0.82 & -0.39 & -2.43 & 0.02 & \\
\hline Education & 0.80 & 0.93 & 0.15 & 0.87 & 0.39 & \\
\hline NPI T1 & -0.09 & 0.03 & -0.57 & $-3.34 * *$ & 0.00 & 0.39 \\
\hline
\end{tabular}

$* p<0.05 ; * * p<0.01$.

$\mathrm{AQ}_{\mathrm{p} \text { vs. C }}$, discrepancy scores on the Awareness Questionnaire between patient and clinician; $\triangle \mathrm{UCLactive,} \mathrm{change} \mathrm{on} \mathrm{Utrecht} \mathrm{Coping} \mathrm{List-}$ active subscale; $\Delta$ UCLpassive, change on Utrecht Coping List-passive subscale; $\triangle U C L a v o i d a n c e$, change on Utrecht Coping List-avoidance subscale.

NPI, Neuropsychiatric Inventory. general population and patients with brain injury without neuropsychiatric symptoms. Increases in avoidance coping styles were statistically significant, although not clinically significant. Active and passive coping styles did not change significantly. The changes in coping could partially be explained by the level of neuropsychiatric symptoms and level of self-awareness at intake but not by self-reported executive functioning.

We found that avoidance coping styles increased in the chronic phase following brain injury in a 6-month period, in which some patients received psychoeducational and/or individualized treatment but with no explicit focus on changing the use of coping styles. Although these changes were statistically significant, they were not clinically significant. Possibly, in order to detect clinical significance, larger samples should be investigated. Active and passive coping styles did not change significantly. Other studies found increases in both passive and avoidance coping styles in the chronic phase following brain injury, in which patients were referred for cognitive rehabilitation. ${ }^{3,13}$ However, findings are not consistent. King and colleagues ${ }^{12}$ found that seeking social support decreased in the first 2 years post-stroke. Active problem solving and avoidance did not change in this time period. An explanation for the absence of changes in active and passive coping may be that a follow-up after 6 months was too short a time for changes in these coping styles to occur. In addition, patients in the present study were almost 11 years post-brain injury. The fact that the patients in the present study had been referred to mental health care indicates that they still suffered from serious problems in their daily life.

Changes in coping have been observed in the first years postinjury in patients with traumatic brain injury. ${ }^{3}$ It may be suggested that the coping repertoires are more stable or even rigid in the chronic phase post-injury. A recent study by Brands and colleagues $^{52}$ showed that coping variability in patients with acquired brain injury was limited even in the first year after being discharged home from acute rehabilitation. In other words, Brands and colleagues ${ }^{52}$ found that patients relied on a defined set of coping options across situations and over time, with only emotion-focused coping decreasing in the first year post-discharge. The finding in the present study that avoidance coping increased in the chronic phase after brain injury suggests that this coping style may be less stable and, if coping is not an explicit focus of treatment, still increases even more than 10 years post-brain injury. Another explanation for the increase in avoidance coping is that patients who struggle to adapt to the changes in their daily functioning and who are referred for specialized care feel overloaded. ${ }^{53}$

In addition to helping patients implicitly handle the sequelae of their injuries, the individual treatment often encompassed helping patients find a balance in their mental activities. This may include advising patients to, at some times, avoid situations that are mentally challenging, such as a birthday party. Because previous research has found that high levels of avoidance coping are maladaptive, ${ }^{7,54}$ it could be suggested that these increases in avoidance coping are maladaptive. This would imply that psychoeducational and/or individualized treatment may increase maladaptive coping styles after brain injury and is therefore not effective. However, it is also possible that for patients who feel overloaded, a balanced use of avoidance coping is recommended. For example, Snell and colleagues ${ }^{19}$ have shown that actively trying to solve problems was associated with poor outcomes after mild traumatic brain injury, suggesting that actively addressing problems might not always be productive. As no measures besides coping were administered at $\mathrm{T} 2$, the relation between increases in avoidance coping and outcome is unknown. 
Individual differences in changes in avoidance coping could partially be explained by neuropsychiatric symptoms. We found that patients with less neuropsychiatric symptoms increased their use of avoidance coping. Although some patients had less neuropsychiatric symptoms than others, they still reported difficulties in their daily life functioning. It is possible that these patients reported low levels of avoidance coping at admission and, as a result, did not avoid mentally challenging situations and felt overloaded the most. ${ }^{55,56}$ Because the psycho-education and individual treatment often was focused on reducing the overload and restoring patients' balance in their mental activities, avoidance coping may have increased in these patients. The decrease in avoidance coping in patients with more neuropsychiatric symptoms may be the consequence of the decrease in neuropsychiatric symptoms over time. Although this is a possibility, it is not known based on the available data.

Further, the level of self-awareness predicted changes in the use of active coping styles. Patients who underestimated their competencies reported greater increases in active coping than patients who accurately estimated and overestimated their difficulties. This is in line with the intervention study of Lundqvist and colleagues ${ }^{17}$ in which an increase in self-awareness and coping strategy behavior was found after a group intervention for awareness in patients with acquired brain injury. It can be hypothesized that awareness levels of patients in the present study increased over the course of the six-month period as a result of the psychoeducational and/or individualized treatment. These increases may have resulted in increases in active coping, assuming that awareness is a prerequisite for developing optimal coping strategies. However, when investigating the relationships per group, no significant associations were found. This is likely the result of the small number of patients per group (from three to 23 patients). Previous studies have suggested that the level of self-awareness is associated with coping styles. Notably, both positive and negative associations have been found. ${ }^{2,16}$

In line with the study of Wolters and colleagues ${ }^{8}$ in which patients with primary behavioral or psychiatric problems after brain injury were excluded, patients reported using passive coping more than the general population. Additionally, we found that the patients in the present study reported even more passive and avoidance coping than the patients in the study by Wolters and colleagues. In other words, the use of passive and possibly avoidance coping increases in general in patients with brain injury in the chronic phase. However, the increases are most prominent in patients with neuropsychiatric symptoms after brain injury, compared with patients without these neuropsychiatric symptoms. In contrast to Wolters and colleagues, ${ }^{8}$ we did not find differences in active coping between the patients in the present study and the general population.

\section{Strengths and limitations}

This study is unique regarding several aspects. First, it focused on patients with prominent neuropsychiatric symptoms after brain injury. Therefore, our results can be generalized to patients with more challenging symptoms. Second, we used a longitudinal design. Therefore, we are able to draw more reliable conclusions about changes in coping over time and the factors that influence changes in coping.

Some limitations also should be acknowledged. Thirty-two significant others participated in the study. The power of the correlation and regression analyses that investigate the relationships between self-awareness, neuropsychiatric symptoms and changes in coping is therefore decreased. More specific analyses investigating associations between subscales of the questionnaires would have decreased the power, and therefore were not performed. We nonetheless found significant effects of neuropsychiatric symptoms on changes in coping styles, suggesting a strong effect.

Further, we used discrepancy scores between self and otherreports to assess awareness and other-reports to assess neuropsychiatric symptoms. Subjective reports can be influenced by one's own psychiatric symptoms and/or perceived burden. We acknowledge this limitation; however, at least for outpatients, it is not possible to objectively assess the level of neuropsychiatric symptoms, and for the AQ, moderate correlations were found for clinicians and caregiver ratings. ${ }^{57}$ In addition, we did not report information about injury severity or controlled for the effect of injury severity on coping or outcomes. Injury severity information often was not available at the referral. However, injury severity has not been suggested to be associated with coping or outcomes in the chronic phase post-injury in earlier studies., ${ }^{23,24}$ Finally, no information on mobility or communication was specifically assessed. Yet, the cognitive profile was assessed, providing at least some information on functional status.

\section{Clinical implications and future research}

This study was an explorative study and replication in larger studies is recommended in order to be able to reliably perform sub group analyses, including by type of injury and time since injury. Further, changes in coping also may be influenced by factors that were not investigated in the present study but may be amenable to treatment, such as self-efficacy. ${ }^{58}$ These factors should be explored in future research. In addition, the influence of treatment focusing on decreasing the use of passive and avoidance coping styles is worth investigating in this patient population. These decreases may lead to a better quality of life and lower levels of depression. This type of treatment has been shown to possibly change the use of maladaptive coping styles into more adaptive coping styles after traumatic brain injury. ${ }^{14}$

Most researchers agree that, in general, passive and avoidance coping are maladaptive. However, there is still a debate about which coping styles are adaptive. In the Coping Scale for Adults, for example, adaptive coping is characterized by actively working on the problem and using humor and enjoyable activities to manage stress. ${ }^{59}$ Recently, research has shown that the use of active coping strategies was adaptive for patients with good executive functioning but maladaptive for patients with low levels of executive functioning. ${ }^{22}$ These findings suggest that whether an active coping strategy is adaptive is dependent on the level of executive functioning. Other factors that influence the adaptability of coping strategies should be explored in future research and consequently considered in coping treatment.

These findings underline the relationship between coping and psychosocial functioning after brain injury. Even more than 10 years post-injury, a large number of patients suffered from low quality of life and high levels of depressive symptoms. More than half of the patients in the present study also reported clinically significant levels of executive dysfunction in daily life. Many patients suffered from irritability and depression, according to their caregiver. By measuring coping preferences, patients who are at risk for low psychosocial functioning, currently and in the long term, can be identified. These patients may benefit from a treatment specifically targeting the use of maladaptive passive coping styles. ${ }^{14,60,61}$ 


\section{Author Disclosure Statement}

No competing financial interests exist.

\section{References}

1. Ponsford J. (2013). Factors contributing to outcome following traumatic brain injury. NeuroRehabilitation 32, 803-815.

2. Anson, K. and Ponsford, J. (2006). Coping and emotional adjustment following traumatic brain injury. J. Head Trauma Rehabil. 21, $248-259$.

3. Wolters Gregorio, G., Gould, K.R., Spitz, G., van Heugten, C.M., and Ponsford J.L. (2014). Changes in self-reported pre- to postinjury coping styles in the first 3 years after traumatic brain injury and the effects on psychosocial and emotional functioning and quality of life. J. Head Trauma Rehabil. 29, E43-E53.

4. Curran, C.A., Ponsford, J.L., and Crowe, S. (2000). Coping strategies and emotional outcome following traumatic brain injury: a comparison with orthopedic patients. J. Head Trauma Rehabil. 15, 1256-1274.

5. Spitz, G., Schonberger, M., and Ponsford, J. (2013). The relations among cognitive impairment, coping style, and emotional adjustment following traumatic brain injury. J. Head Trauma Rehabil. 28, $116-125$.

6. Tomberg, T., Toomela, A., Ennok, M., and Tikk, A. (2007). Changes in coping strategies, social support, optimism and health-related quality of life following traumatic brain injury: a longitudinal study. Brain Inj. 21, 479-488.

7. Wood, R.L. and Doughty, C. (2013). Alexithymia and avoidance coping following traumatic brain injury. J. Head Trauma Rehabil. 28, 98-105.

8. Wolters, G., Stapert, S., Brands, I., and van Heugten, C. (2011). Coping following acquired brain injury: Predictors and correlates. J. Head Trauma Rehabil. 26, 150-157.

9. Dawson, D.R., Schwartz, M.L., Winocur, G., and Stuss, D.T. (2007). Return to productivity following traumatic brain injury: cognitive, psychological, physical, spiritual, and environmental correlates. Disabil. Rehabil. 29, 301-313.

10. Boynton De Sepulveda, L.I., and Chang, B. (1994). Effective coping with stroke disability in a community setting: the development of a causal model. J. Neurosci. Nurs. 26, 193-203.

11. Sinyor, D., Amato, P., Kaloupek, D.G., Becker, R., Goldenberg, M., and Coopersmith, H. (1986). Post-stroke depression: relationships to functional impairment, coping strategies, and rehabilitation outcome. Stroke 17, 1102-1107.

12. King, R.B., Shade-Zeldow, Y., Carlson, C.E., Feldman, J.L., and Philip, M. (2002). Adaptation to stroke: a longitudinal study of depressive symptoms, physical health, and coping process. Top. Stroke Rehabil. 9, 46-66.

13. Wolters, G., Stapert, S., Brands, I., and van Heugten, C. (2010). Coping styles in relation to cognitive rehabilitation and quality of life after brain injury. Neuropsychol. Rehabil. 20, 587-600.

14. Anson, K., and Ponsford, J. (2006). Evaluation of a coping skills group following traumatic brain injury. Brain Inj. 20, 167-178.

15. Medley, A.R., Powell, T., Worthington, A., Chohan, G., and Jones, C. (2010). Brain injury beliefs, self-awareness, and coping: a preliminary cluster analytic study based within the self-regulatory model. Neuropsychol. Rehabil. 20, 899-921.

16. Kortte, K.B., Wegener, S.T., and Chwalisz, K. (2003). Anosognosia and denial: their relationship to coping and depression in acquired brain injury. Rehabil. Psychol. 48, 131-136.

17. Lundqvist, A., Linnros, H., Orlenius, H., and Samuelsson, K. (2010). Improved self-awareness and coping strategies for patients with acquired brain injury—a group therapy programme. Brain Inj. 24, 823-832.

18. Taylor, S.E. and Stanton, A.L. (2007). Coping resources, coping processes, and mental health. Ann. Rev. Clin. Psychol. 3, 377-401.

19. Snell, D.L., Siegert, R.J., Hay-Smith, E.J.C., and Surgenor, L.J. (2011). Associations between illness perceptions, coping styles and outcome after mild traumatic brain injury: Preliminary results from a cohort study. Brain Inj. 25, 1126-1138.

20. Ponsford, J.L., Sloan, S., and Snow, P. (2012). Traumatic Brain Injury: Rehabilitation for Everyday Adaptive Living, 2nd ed. Psychology Press (Taylor and Francis Group): New York.
21. Krpan, K.M., Levine, B., Stuss, D.T., and Dawson, D.R. (2007). Executive function and coping at one-year post traumatic brain injury. J. Clin. Exp. Neuropsychol. 29, 36-46.

22. Wolters Gregório, G., Ponds, R.W.H.M., Smeets, S.M.J., Jonker, F., Pouwels, C.G.J.G., Verhey, F.R., and van Heugten, C.M. (2015). Associations between executive functioning, coping, and psychosocial functioning after acquired brain injury. Br. J. Clin. Psychol. 54, 291306

23. Herrmann, M., Curio, N., Petz, T., Synowitz, H., Wagner, S., Bartels, C., and Wallesch, C.W. (2000). Coping with illness after brain diseases - a comparison between patients with malignant brain tumors, stroke, Parkinson's disease and traumatic brain injury. Disabil. Rehabil. 22, 539-546.

24. Finset, A. and Andersson, S. (2000). Coping strategies in patients with acquired brain injury: relationships between coping, apathy, depression and lesion location. Brain Inj. 14, 887-905.

25. Fann, J.R., Burington, B., Leonetti, A., Jaffe, K., Katon, W.J., and Thompson, R.S. (2004). Psychiatric illness following traumatic brain injury in an adult health maintenance organization population. Arch. Gen. Psychiatry 61, 53-61.

26. Johnston, M.V. and Hall, K.M. (1994). Outcomes evaluation in TBI Rehabilitation. Part I: overview and system principles. Arch. Phys. Med. Rehabil. 75(12 Spec No), SC1-9.

27. Bryant, R.A., O'Donnell, M.L., Creamer, M., McFarlane, A.C., Clark, C.R., and Silove, D. (2010). The psychiatric sequelae of traumatic injury. Am. J. Psychiatry 167, 312-320.

28. Vaishnavi, S., Rao, V., and Fann, J.R. (2009). Neuropsychiatric problems after traumatic brain injury: unraveling the silent epidemic. Psychosomatics 50, 198-205.

29. Chemerinski, E. and Robinson, R.G. (2000). The neuropsychiatry of stroke. Psychosomatics 41, 5-14.

30. Rao, V. and Lyketsos, C. (2000). Neuropsychiatric sequelae of traumatic brain injury. Psychosomatics 41, 95-103.

31. Wisdom, N.M., Callahan, J.L., and Shaw, T.G. (2010). Diagnostic utility of the structured inventory of malingered symptomatology to detect malingering in a forensic sample. Arch. Clin. Neuropsychol. 25, 118-125.

32. Spreen, O. and Strauss, E. (1998). A Compendium of Neuropsychological Tests: Administration, Norms, and Commentary, 2nd ed. Oxford University Press: New York.

33. Schmand, B., Houx, P., and de Koning, I. (2003. The Stroop colour word test, the Trail Making Test, the Rivermead, Behavioural Memory Test, Dutch norms. Netherlands Institute of Psychologists, section Neuropsychology. Available at: www.psynip.nl. Accessed September 26, 2015.

34. Stroop J. (1935). Studies in interference in serial verbal reactions. J. Exp. Psychol. 18, 643-662.

35. De Bie, S.E. (1987). [Standard questions 1987: Proposal for uniformization of questions regarding background variables and interviews]. Leiden University Press: Leiden, the Netherlands.

36. American Psychiatric Association. (2000). Diagnostic and Statistical Manual of Mental Disorders DSM-IV-TR Fourth Edition (Text Revision). APA: Arlington, VA

37. Van Baalen, B., Ribbers, G.M., Medema-Meulepas, D., Pas, M.S., Odding, E., and Stam, H.J. (2007). Being restricted in participation after a traumatic brain injury is negatively associated by passive coping style of the caregiver. Brain Inj. 21, 925-931.

38. Schreurs, P.J.G., van de Willige, G., Tellegen, B., and Brosschot, J.F. (1988). [The Utrecht Coping List: Manual of the UCL]. Swets \& Zeitlinger: Lisse, Netherlands.

39. Schreurs, P.J.G., van de Willege, G., Brosschot, J.F., Tellegen, B., and Graus, G.M.H. (1993). [The Utrecht Coping List: UCL. Dealing with problems and events]. Swets en Zeitlinger: Utrecht, the Netherlands.

40. Grace, J. and Malloy, P.F. (2001). Frontal Systems Behavior Scale (FrSBe): Professional Manual. Psychological Assessment Resources: Lutz, FL.

41. Malloy, P. and Grace, J. (2005). A review of rating scales for measuring behavior change due to frontal systems damage. Cogn. Behav. Neurol. 18, 18-27.

42. Cummings J.L. (1994). The Neuropsychiatric Inventory: comprehensive assessment of psychopathology in dementia. Neurology 44, 2308-2314.

43. Cummings J.L. (1997). The Neuropsychiatric Inventory: assessing psychopathology in dementia patients. Neurology 48, S10-S16.

44. Sherer, M., Hart, T., and Nick, T.G. (2003). Measurement of impaired self-awareness after traumatic brain injury: A comparison of the 
Patient Competency Rating Scale and the Awareness Questionnaire. Brain Injury 17, 25-37.

45. Sherer, M., Bergloff, P., Boake, C., High, W., Jr., and Levin, E. (1998). The Awareness Questionnaire: Factor structure and internal consistency. Brain Injury 12, 63-68.

46. Prigatano, G.P. and Altman, I.M. (1990). Impaired awareness of behavioral limitations after traumatic brain injury. Arch. Phys. Med. Rehabil. 71, 1058-1064.

47. Fugl-Meyer, A.R., Branholm, I.B., and Fugl-Meyer, K.S. (1991), Happiness and domain specific life satisfaction in adult northern Swedes. Clin. Rehabil. 5, 25-33.

48. Visser-Meily, A., Post, M., Schepers, V., and Lindeman, E. (2005). Spouses' quality of life 1 year after stroke: prediction at the start of clinical rehabilitation. Cerebrovasc. Dis. 20, 443-448.

49. Kroenke, K., Spitzer, R.L., and Williams, J.B. (2001). The PHQ-9: validity of a brief depression severity measure. J. Gen. Intern. Med. 16, 606-613.

50. Fann, J.R., Bombardier, C.H., Dikmen, S., Esselman, P., Warms, C.A. Pelzer, E., Rau, H., and Temkin, N. (2005). Validity of the Patient Health Questionnaire-9 in assessing depression following traumatic brain injury. J. Head Trauma Rehabil. 20, 501-511.

51. Arbuthnott, K. and Frank, J. (2000). Trail making test, part B as a measure of executive control: validation using a set-switching paradigm. J. Clin. Exp. Neuropsychol. 22, 518-528.

52. Brands, I., Kohler, S., Stapert, S., Wade, D., and van Heugten, C. (2014). How flexible is coping after acquired brain injury? A 1-year prospective study investigating coping patterns and influence of self-efficacy, executive functioning and self-awareness. J. Rehabil. Med. 46, 869-875.

53. Ruff, R.M. and Chester, S.K. (2014). Treating anxiety and stress, in: Effective Psychotherapy for Individuals With Brain Injury. Guilford Publications: New York

54. King, R.B., Carlson, C.E., Shade-Zeldow, Y., Bares, K.K., Roth, E.J., and Heinemann, A.W. (2001). Transition to home care after stroke: depression, physical health, and adaptive processes in support persons. Res. Nursing Health 24, 307-323.
55. Grady, M.F., Master, C.L., and Gioia, G.A. (2012). Concussion pathophysiology: rationale for physical and cognitive rest. Pediatr. Ann. 41, 377-382.

56. Brown, N.J., Mannix, R.C., O’Brien, M.J., Gostine, D., Collins, M.W., and Meehan, W.P., 3rd. (2014). Effect of cognitive activity level on duration of post-concussion symptoms. Pediatrics 133 , e299-e304.

57. Smeets, S.M., Ponds, R.W., Verhey, F.R., and van Heugten, C.M (2011). Psychometric properties and feasibility of instruments used to assess awareness of deficits after acquired brain injury: a systematic review. J. Head Trauma Rehabil. 27, 433-442.

58. Brands, I., Kohler, S., Stapert, S., Wade, D., and van Heugten, C. (2014). Influence of self-efficacy and coping on quality of life and social participation after acquired brain injury: a 1-year follow-up study. Arch. Phys. Med. Rehabil. 95, 2327-2334.

59. Frydenberg, E. and Lewis, R. (1997). Coping Scale for Adults. The Australian Council for Educational Research: Melbourne, Victoria, Australia.

60. Backhaus, S.L., Ibarra, S.L., Klyce, D., Trexler, L.E., and Malec, J.F. (2010). Brain injury coping skills group: a preventative intervention for patients with brain injury and their caregivers. Arch. Phys. Med. Rehabil. 91, 840-848.

61. Doering, B. and Exner, C. (2011). Combining neuropsychological and cognitive-behavioral approaches for treating psychological sequelae of acquired brain injury. Curr. Opin. Psychiatry 24, 156-161.

Address correspondence to:

Caroline M. van Heugten, PhD Maastricht University

Department of Psychiatry and Neuropsychology

PO Box 616 (drt12) 6200 MD Maastricht, the Netherlands

E-mail: c.vanheugten@maastrichtuniversity.nl 